\title{
Population Dynamics of Intermediate-Host Snails in the White Nile River, Sudan: A Year-Round Observational Descriptive Study
}

\author{
Hassan A. H. A. Ismail, ${ }^{1,}$, , Abed el Aziz A. el R. M. Ahmed ${ }^{2, \dagger}$, Young-Ha Lee ${ }^{3}$, Mousab Siddig Elhag', \\ Youngjin $\mathrm{Kim}^{4}$, Seungman $\mathrm{Cha}^{4,5, *}$ (iD, Yan $\mathrm{Jin}^{6, *}$ (i) \\ ${ }^{1}$ Communicable and Non-Communicable Diseases Control Directorate, Federal Ministry of Health, Khartoum, Sudan; ${ }^{2}$ Schistosmaisis Research \\ Laboratory, Zoology Department, Faculty of Science, University of Khartoum; ${ }^{3}$ Department of Infection Biology and Department of Medical Science, \\ Chungnam National University School of Medicine, Daejeon 35015, Korea; ${ }^{4}$ Department of Global Development and Entrepreneurship, Graduate \\ School of Global Development and Entrepreneurship, Handong Global University, Pohang 37554, Korea; ${ }^{5}$ Department of Disease Control, London \\ School of Hygiene \& Tropical Medicine, London, UK; 'Department of Microbiology, Dongguk University College of Medicine, Gyeongju 38067, Korea
}

\begin{abstract}
We aimed to explore the population dynamics of snail in 3 sites of the White Nile in Sudan. More specifically, we aimed to investigate the annual patterns of snail populations that act as intermediate hosts of schistosomes and monthly snail infection rates and ecological characteristics presumably related to snail populations. We collected snails for 1 year monthly at 3 different shore sites in the vicinity of El Shajara along the White Nile river in Khartoum State, Sudan. In addition, we measured air and water temperatures, water turbidities, vegetation coverages, and water depths and current speeds. Most of the collected snails were Biomphalaria pfeifferi and Bulinus truncatus. The population densities of snails and their infection rates varied across survey sites. The collected snails liberated S. mansoni and S. haematobium cercariae as well as Amphistome and Echinostome cercariae. Infected snails were found during March-June. The ecological characteristics found to be associated with the absence of snails population were: high turbidity, deep water, low vegetation coverage (near absence of vegetation), high water temperature, and high current speed. To our knowledge, this is the first longitudinal study of the snail population and ecological characteristics in the main basin of the White Nile river.
\end{abstract}

Key words: Snail population, ecological characteristics, schistosomiasis, the White Nile, Sudan

\section{INTRODUCTION}

Schistosomiasis is a waterborne parasitic disease in tropical and subtropical areas and is second only to malaria in terms of disease burden [1] The transmission of human schistosomes is a complex process with a vicious transmission cycle involving man as a definitive host and reservoir of adult schistosomes.

Pulmonate snails of the family Planorbidae are the intermediate hosts of human schistosomes in Africa, the Middle East, the Caribbean Islands, and South America. Two species of truly aquatic, basommatophoran genera Biomphalaria and Bulinus

- Received 30 December 2020, revised 22 March 2021, accepted 31 March 2021. *Corresponding authors (seungman.cha@handong.edu; jinyan1024@gmail.com)

${ }^{\dagger}$ These authors have equally contributed to this paper.

(c) 2021, Korean Society for Parasitology and Tropical Medicine

This is an Open Access article distributed under the terms of the Creative Commons Attribution Non-Commercial License (https://creativecommons.org/licenses/by-nc/4.0) which permits unrestricted non-commercial use, distribution, and reproduction in any

medium, provided the original work is properly cited. transmit S. mansoni and S. haematobium. Biomphalaria and Bulinus are aquatic hermaphroditic snails, and transmission of schistosomiasis may occur in different types of waterbodies [2]. The risk of becoming infected after contact with an infested waterbody depends on duration of water contact, extent of body exposure, and time of day $[3,4]$.

In Sudan, the majority of previous malacological studies have been performed on the canalization systems of different irrigation schemes, which are thought to have contributed to increasing the prevalence and intensity of schistosomiasis in surrounding areas [5-13]. Furthermore, snail population densities have been reported to exhibit marked seasonal and annual fluctuations [14-16].

However, few studies have been conducted on snail populations along the White Nile. The Federal Ministry of Sudan and its partners are trying to adopt a more comprehensive approach to schistosomiasis elimination across Sudan. The Korean government has implemented schistosomiasis control along the 
White Nile during the past 10 years with focus on preventive chemotherapy and pledged to invest in schistosomiasis elimination in Sudan over the next 4 years. A recent nationwide Sudanese survey on schistosomiasis showed its prevalence had fallen to below $1 \%$ in many parts of the country. We considered that understanding snail population dynamics and related ecological factors is a prerequisite for designing appropriate control and elimination programs. In addition, as has been previously reported, information on the epidemiology of schistosomiasis, particularly on transmission patterns in endemic areas, including those along the White Nile river, will undoubtedly aid the design and implementation of control strategies [17].

We aimed to explore snail population dynamics at 3 sites on the White Nile in Sudan. More specifically, we sought to document annual changes in snail populations, their monthly infection rates, and ecological characteristics ostensibly related to snail populations. To the best of our knowledge, this is the first longitudinal study to address population dynamics of snail and ecological characteristics in the main river basin of the White Nile.

\section{MATERIALS AND METHODS}

\section{Study area}

We selected 3 spots along the White Nile in the El Shajara Administration Unit, Khartum State, Sudan.

\section{Khartoum State}

Khartoum State is situated in the center of Sudan and forms a rectangle that is traversed from South to North by the Nile and its 2 tributaries, the White and Blue Nile. The total population of Khartoum State is about 7.7 million [18]. There is a continuous and active influx of individuals from all other states of the country mainly due to drought, desertification, civil unrest, and economic reasons. The state has semi-arid climate, with an average rainfall of $150-250 \mathrm{~mm}$ from July to September, which accounts for $90 \%$ of annual rainfall. The Blue and White Nile flood peaks occur in August, during which plains around their banks are submerged.

\section{White Nile river}

The source of the Nile is Lake Victoria at Ripon Falls near Jinja, Uganda, where it is referred to the Victoria Nile. It flows for approximately $500 \mathrm{~km}$ through Lake Kyoga, until it reaches
Lake Albert, from which it flows to Sudan; this stretch of the river is called the Albert Nile. When it flows into Sudan, it is called Bahr al Jabal "River of the Mountain". This section of the river is $716 \mathrm{~km}$ long and flows into a small lagoon called Lake No, and subsequently, the river is called Bahr Abyad or the White Nile until it and the Blue Nile merge to form the Nile at Khartoum.

\section{El Shajara Administration Unit}

We surveyed snail populations and ecological factors at 3 locations in El Shajara Administration Unit on the east bank of the White Nile. The total population in this area is about 250,000 and it contains 25 primary and 2 higher secondary schools. We selected this area based on the preliminary findings of the malacological surveys done by the parasitologists of Schistosomiasis Research Laboratory, Khartoum University and the Federal Ministry of Heal the National Control Program of Bilharzia, Federal Ministry of Health. This area has been reported to have many "hot spots" in terms of snail numbers and human/river water contact.

\section{Snail sampling and monitoring of ecological factors}

We conducted malacological field surveys to collect snails at 3 sites along the shore of the White Nile in El Shajara Administration Unit, that is, in the North El Shajara Irrigation area, the South El Shajara Irrigation area, and the South Railway area monthly from May 2005 to April 2006. At each site, we collected snails from 10 spots using "the scooping technique" with a standardized scoop, comprised of a flat wire mesh size (1.5 mm mesh size) mounted on a metal frame $(40 \times 30 \mathrm{~cm})$ with a $2 \mathrm{~m}$ long metal handle. At each spot, we dipped the scoop perpendicular at $2 \mathrm{~m}$ offshore and dragged it along the bottom. Twenty scoops were taken at a distance of $2 \mathrm{~m}$ between scoops at each site (i.e., 2 scoops per spot). The snails obtained were placed in a plastic aquarium and transported to the Schistosomiasis Research Laboratory, Department of Zoology, Faculty of Science, University of Khartoum.

We monitored a range of ecological factors believed to affect the population dynamics of snails on days of snail collection. These factors were: air and water temperature, water turbidity, water depth, current speed, and vegetation cover. Air and water temperatures were measured using a mercury thermometer $\left(0-50^{\circ} \mathrm{C}\right)$. At each site, we immersed the thermometer $15 \mathrm{~cm}$ below the water surface and left it in position for $5 \mathrm{~min}$. Temperatures were measured at noon. Water temperatures were 
measured 3 times per site at each visit and are reported as mean monthly water temperatures, and air temperatures were measured once per site at noon during each visit.

We measured water depth by immersing the scoop vertically to the river bottom, marking the scoop handle, and measuring depth using a tape measure. We repeated this water depth measurement 3 times at each spot during each visit, and report mean monthly water depths. The methods used to determine current speeds and vegetation coverage were somewhat arbitrary. We simply categorized current speed as fast, moderate, or slow based on personal experience over an extended period of observation of currents by the first author. Vegetation coverage was quantified by assessing percentage of water surface area covered by vegetation at sampling spots. Water turbidity was assessed while submerging the scoop, if the iron support of the mesh was not visible $20,20-50 \mathrm{~cm}$, or $>50 \mathrm{~cm}$ from the surface, we categorized turbidity as high, moderate, or low.

\section{Identification of snails}

For every survey, we pooled snails collected at each of the 3 sites in water-filled plastic containers containing a few plants from same sites. Travel back to the laboratory took 2-3 hr. After cleaning snails, they were identified using the Field Guide to African Freshwater Snails [19].

\section{Examination of snail infection}

We started examining the infectious status of snails on the same days as visits and continued this examination for 4 weeks on a weekly basis using the natural emergence technique. We placed 20 snails into 1 beaker, containing $200 \mathrm{ml}$ of dechlorinated tap water and placed them under strong artificial illumination at $20-25^{\circ} \mathrm{C}$ for $4-6 \mathrm{hr}$. The emergence of cercariae was checked at regular intervals, since emerged cercariae can encyst on external substrates or re-enter snails quickly. When cercariae emerged in a beaker, snails were transferred to small glass bottles for individual screening. The numbers of snails shedding cercariae were recorded and those not shedding cercariae were re-examined weekly for a month to obtain exact infection rates.

\section{Identification of cercariae}

Cercariae were stained with iodine and the Ehrlich's hematoxylin, as previously described [20], to better observe morphological features and were then identified at the sub-type, genus, and species levels using the morphology criteria provid- ed in the Guide to the identification of cercariae from African freshwater snails" by Frandsen and Christensen [21]. These criteria included the species of snail-shedding cercariae, cercarial swimming behavior, and resting position. In addition, cercarial development, that is, encystation on an external substrate, encystation in a second intermediate-host were recorded. The morphological features and the main diagnostic characteristics used to identify cercaria included: general appearance, tegument, body suckers, alimentary system, excretory system gland cells, genital primordium and shape, and relative tail dimensions. These were obtained by viewing cercaria in water at 20$25^{\circ} \mathrm{C}$ of sufficient volume to allow normal behavior under a stereomicroscope.

The identification of emerged cercariae at the major type level was carried out using living (unstained) cercarial specimens on glass slides. Briefly, a few cercariae were taken from an emergence beaker using a pipette and transferred in a drop of water onto a glass slide and cover-slipped. Excess water was removed by touching one side of the coverslip with a strip of filter paper. This removal immobilized the cercariae and caused slight flattening, which allowed external and internal structures to be more easily observed.

\section{Statistical analysis}

We run non-parametric analysis to investigate correlation between ecological factors and snail population because of small sample size. We used the spearman rank correlation test to explore any association between snail population and ecological factors of continuous variables (air temperature, water temperature, vegetation coverage, water depth) and the Kruskal-Wallis test for categorical variables (water turbidity and water speed). We used SPSS 23 (IBM, Armonk, New York, USA).

\section{RESULTS}

The monthly distributions of densities of snails associated with or not associated with human schistosomiasis are summarized in Table 1 and illustrated in Fig. 1. The percentage of intermediate-host snails (Biomphalaria pfeifferi and Bulinus truncatus) was slightly larger than that of snails infected with non-human trematodes (Physa acuta, Pila ovata, Melanoides tuberculata and Cleopatra bulimoides).

We observed a continuous increase in snail numbers from November to April and then a gradual decline to July. To our surprise, we did not find a single snail from August through 
Table 1. Monthly distribution of snails associated with human or non-human schistosomiasis

\begin{tabular}{|c|c|c|c|c|c|c|c|c|c|c|c|c|}
\hline \multirow{2}{*}{ Month } & \multicolumn{4}{|c|}{ Human schistosomiasis } & \multicolumn{6}{|c|}{ Non-human schistosomiasis } & \multirow{2}{*}{ Total } & \multirow{2}{*}{$\%$} \\
\hline & $\mathrm{Bt}$ & $\mathrm{Bp}$ & Sum & $\%$ & $\mathrm{Cb}$ & Mt & $\mathrm{Pa}$ & Po & Sum & $\%$ & & \\
\hline May & 597 & 1,097 & 1,694 & 18.2 & 732 & 273 & 324 & 139 & 1,468 & 17.8 & 3,162 & 18.0 \\
\hline June & 294 & 1,090 & 1,384 & 14.9 & 598 & 296 & 213 & 148 & 1,255 & 15.3 & 2,639 & 15.1 \\
\hline July & 201 & 486 & 687 & 7.4 & 458 & 151 & 139 & 110 & 858 & 10.4 & 1,545 & 8.8 \\
\hline August & 0 & 0 & 0 & 0 & 0 & 0 & 0 & 0 & 0 & 0 & 0 & 0.0 \\
\hline September & 0 & 0 & 0 & 0 & 0 & 0 & 0 & 0 & 0 & 0 & 0 & 0.0 \\
\hline October & 0 & 0 & 0 & 0 & 0 & 0 & 0 & 0 & 0 & 0 & 0 & 0.0 \\
\hline November & 99 & 109 & 208 & 2.2 & 63 & 0 & 19 & 0 & 82 & 1 & 290 & 1.7 \\
\hline December & 191 & 242 & 433 & 4.7 & 155 & 26 & 65 & 27 & 273 & 3.3 & 706 & 4.0 \\
\hline January & 303 & 352 & 655 & 7 & 300 & 40 & 186 & 58 & 584 & 7.1 & 1,239 & 7.1 \\
\hline February & 475 & 521 & 996 & 10.7 & 490 & 187 & 255 & 134 & 1,066 & 13 & 2,062 & 11.8 \\
\hline March & 738 & 657 & 1,395 & 15 & 705 & 149 & 272 & 149 & 1,275 & 15.5 & 2,670 & 15.2 \\
\hline April & 995 & 854 & 1,849 & 19.9 & 765 & 138 & 335 & 127 & 1,365 & 16.6 & 3,214 & 18.3 \\
\hline Total & 3,893 & 5,408 & 9,301 & 100 & 4,266 & 1,260 & 1,808 & 892 & 8,226 & 100 & 17,527 & 100.0 \\
\hline$\%$ & 42 & 58 & 53 & & 52 & 15 & 22 & 11 & 47 & & 100 & \\
\hline
\end{tabular}

Bt, Bulinus truncates; Bp, Biomphalaria pferifferi; Cb, Cleopatra bulimoides; Mt, Melanoides tuberculatus; Pa, Physa acuta; Po, Pila ovata.

A

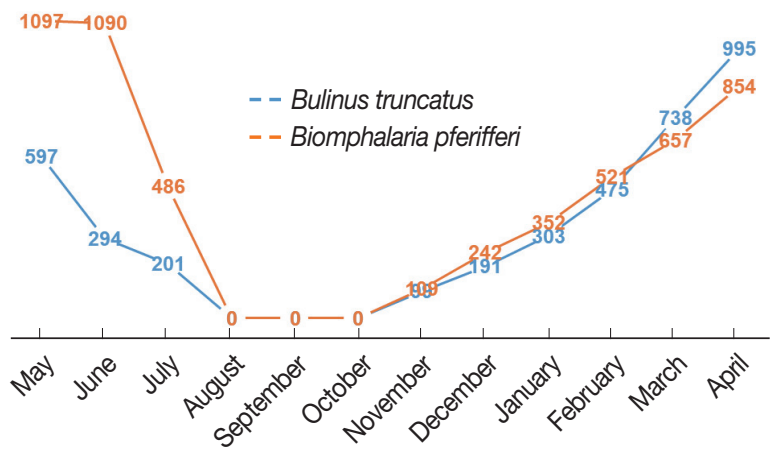

B

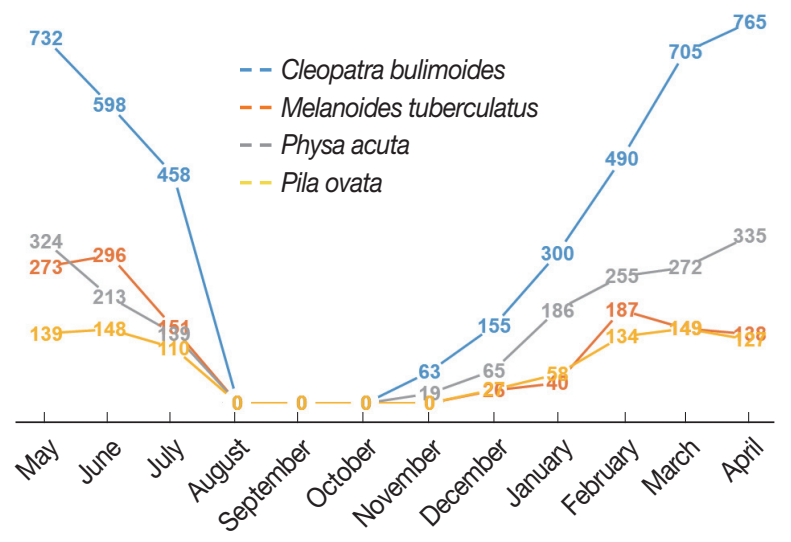

Fig. 1. Monthly distributions of snails collected at 3 sites: (A) Human bilhazia (B) Non-human bilhazia.

October. The seasonal distribution pattern was consistent across survey sites and for snail types. Biomphalaria pfeifferi was slightly more numerous than Bulinus truncatus, but varied by site. Most of the snails that act as human intermediate hosts of Schistosomiasis were of Biomphalaria pfeifferi at the South Railway (66\%) and North El Shajara (61\%), but Bulinus truncatus was more populous in South El Shajara (63\%). Snail densities differed at the 3 sites, altho. Almost half of the human intermediate snails collected were from the North El Shajara site (47\%), followed by the South Railway (34\%) and the South El Shajara site (19\%). For non-human intermediate snails, the largest number of snails collected were of Cleopatra bulimoides (50\%), followed by Physa acuta (28.5\%), Melanoides tuberculata (12.6\%), and Pila ovata (8.9\%). Of these, $42 \%$ were collected in North El Shajara AU.

\section{Temperature and vegetation coverage}

The seasons in Sudan are divided into a cold season (November-February), a hot season (March-June), and a rainy season (July-October, Fig. 2). Air and water temperatures were found to vary accordingly. Water temperatures ranged from 23 to $31^{\circ} \mathrm{C}$ over the year and were similar at the 3 sites with fluctuations of around $1^{\circ} \mathrm{C}$. Vegetation cover gradually increased from November till May and declined till August (Fig. 3). No vegetation coverage was observed at any site from August to October due to flooding.

\section{Water depth, turbidity, and current speed}

Water depths at $1 \mathrm{~m}$ offshore ranged from 15 to $30 \mathrm{~cm}$ (Fig. 4). The water was clear in January-May and turbid from June through December with peak turbidity in August-September 
Table 2. Water turbidities and current speeds

\begin{tabular}{|c|c|c|c|c|c|c|}
\hline \multirow{2}{*}{ Months } & \multicolumn{2}{|c|}{ South EI Shajara } & \multicolumn{2}{|c|}{ North El Shajara } & \multicolumn{2}{|c|}{ South the railway EI Shajara } \\
\hline & Turbidity & Speed & Turbidity & Speed & Turbidity & Speed \\
\hline May & Clear & Slow & Clear & Slow & Clear & Slow \\
\hline June & Moderate & Slow & Moderate & Slow & Clear & Slow \\
\hline July & Moderate & Fast & High & Slow & Moderate & Moderate \\
\hline August & High & Fast & High & Fast & High & Fast \\
\hline September & High & Fast & Moderate & Fast & High & Fast \\
\hline October & Moderate & Fast & Moderate & Moderate & Moderate & Fast \\
\hline November & Moderate & Moderate & Moderate & Moderate & Moderate & Fast \\
\hline December & Moderate & Moderate & Moderate & Slow & Moderate & Moderate \\
\hline January & Clear & Moderate & Clear & Slow & Clear & Moderate \\
\hline February & Clear & Slow & Clear & Slow & Clear & Slow \\
\hline March & Clear & Slow & Clear & Slow & Clear & Slow \\
\hline April & Clear & Slow & Clear & Slow & Clear & Slow \\
\hline
\end{tabular}

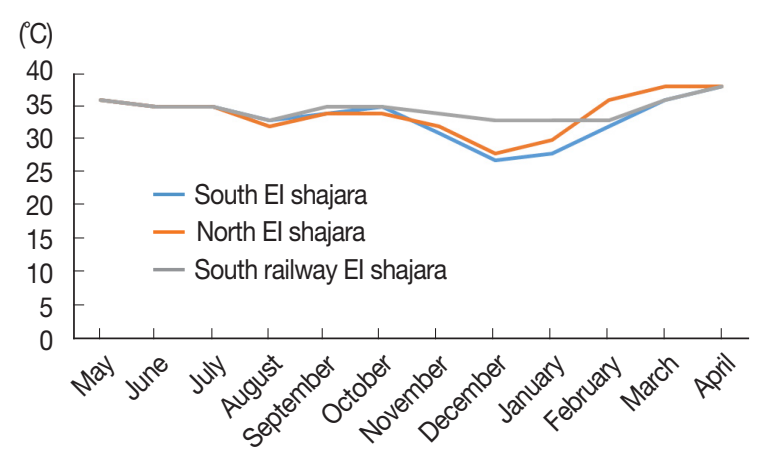

Fig. 2. Water temperature (Celcius degree, mean value).

(Table 2). Water flow was slow from February through June and higher from July through January with peak flow between August and October (Table 2).

Fig. 5A summarizes infection snail rates with human cercariae by month. The overall infection rate of the 2 snails was $1.03 \%(96 / 9,301)$. Of the 5,408 Biomphalaria pfeifferi snails collected, 52 were found to be liberating $S$. mansoni cercariae (infection rate: 0.96\%), and of the 3,893 Bulinus truncatus snails, 44 liberated S. haematobium cercariae (infection rate: 1.13\%). Bulinus truncatus snails were found to be infected with urinary schistosomiasis during March-May at all 3 sites and in June at the South Railway site. Biomphalaria pfeifferi snails were infected with intestinal schistosomiasis from March to June, at all 3 sites.

Fig. 5B illustrates the seasonal dynamics of Biomphalaria pfeifferi and Bulinus truncatus snail infection rates with non-human trematodes. Bulinus truncatus snails were infected with non-human trematodes from January to June, and Biomphalaria pfeifferi snails were infected from January to July. Of 548 Biomphalaria pfeifferi snails, 31 were found to liberate trema-

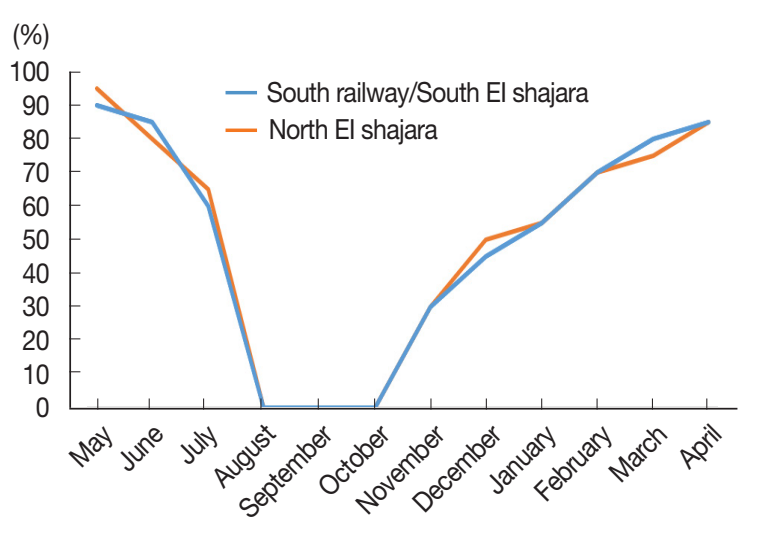

Fig. 3. Vegetation coverage (\%, mean value).

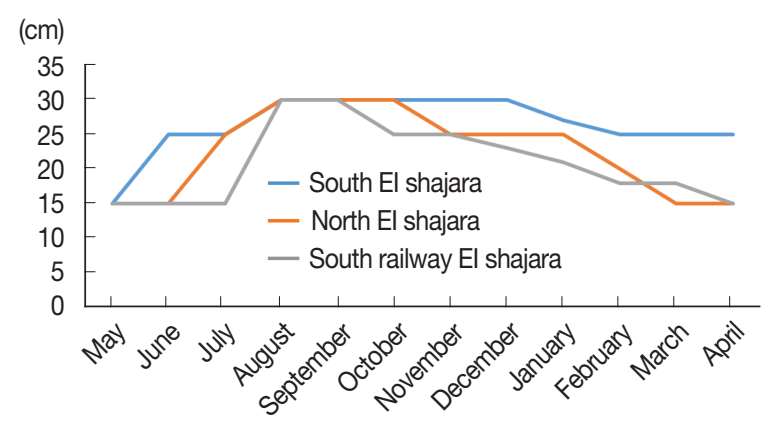

Fig. 4. Water depth by site (cm).

tode cercariae (infection rate: 0.95\%), and of 3,893 Bulinus truncatus snails, 57 liberated trematode cercariae (infection rate: $1.5 \%)$.

Table 3 indicates that ecological factors have strong association with snail populations except for the water temperature. 

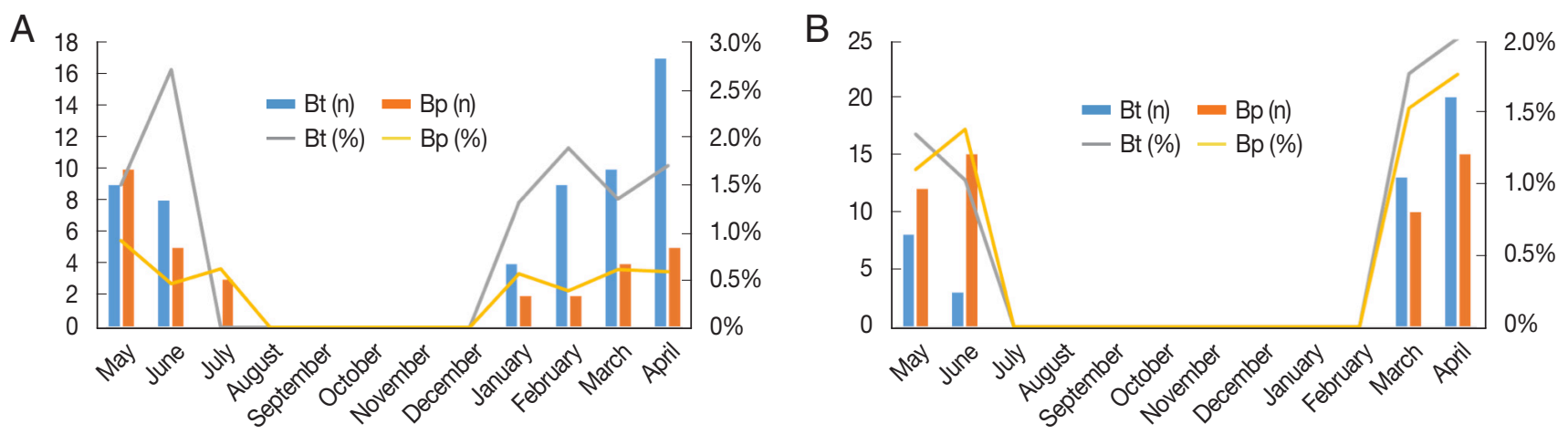

Fig. 5. Number and percentage of infected snails: (A) Human bilhazia, Bt, Bulinus truncates; Bp, Biomphalaria pferifferi, (B) Non-human bilhazia, Bt, Bulinus truncates; Bp, Biomphalaria pferifferi (left Y-axis: number of infected snails; right Y-axis: percentage of infected snails).

Table 3. Association between ecological factors and snail population

\begin{tabular}{lcc}
\hline Ecological factor & Category/Range & $P$-value \\
\hline Categorical & & \\
Water speed & Slow, moderate, and fast & $<0.001$ \\
Water turbidity & Clear, moderate, and turbid & $<0.001$ \\
Continuous & & \\
Vegetation coverage & $0-92 \%$ & $<0.001$ \\
Water depth & $15-30 \mathrm{~cm}$ & $<0.001$ \\
Air temperature & $27-38^{\circ} \mathrm{C}$ & $<0.001$ \\
Water temperature & $23-31^{\circ} \mathrm{C}$ & 0.13 \\
\hline
\end{tabular}

\section{DISCUSSION}

This study shows snail populations peaked in April or May and that snails suddenly disappeared around August-September, reappeared in October, and then increased till April or May. We infer that the dynamics of snail populations are associated with water turbidity, water depth, current speed, and vegetation coverage. It is puzzling that water temperature is not associated with snail population whereas air temperature has strong correlation. It might be because the range of water temperature is relatively narrow over year unlike air temperature. We also think that air temperature might have affected vegetation coverage. It is worth noting that during the rainy season (August-September), schistosomiasis infected snails were absent and that during this period no vegetation coverage was observed at the 3 survey sites. On the other hand, intermediate-host snails exponentially increased from November through April, during which the water was clean, and the temperature was low.

Thus, it appears that the ecological characteristics associated with the absence of snails are: high turbidity, deep water, near absence of vegetation coverage, high water temperature, and high current speed. However, we suppose that there probably are associations between these variables, for example between water depth and vegetation cover.

Many researchers have linked seasonal fluctuations of faunal and floral forms to physical, chemical, and biological factors such as rainfall, temperature, vegetation cover, water turbidity, and current speed [6,21-23]. The relatively small number of snails found in South El Shajara AU (19\%) may have been due to deeper water and faster current speeds. Like humanschistosomiasis snails, intermediate-host snails of non-human trematodes were also most affected by water depth and speed. It was interesting that Cleopatra bulimoides accounted for most of these snails at 50\%, followed by Physa acuta at $28.5 \%$ and Melanoides tuberculata at $12.6 \%$.

A study in Gezira detected a significant build-up in the population of Biomphalaria snails in a minor canal during the summer season (April-June), which contrasts with our findings [24]. We consider that spreading molluscicides and drying these canals probably affected the bionomics of these snails. In a study conducted in the Nuba Mountains [25], 77 $\%$ of snails collected throughout the year were found in August-November. Furthermore, the snails collected in AugustNovember were $100 \%$ infected. However, the ecological characteristics in this area are quite different from those of the survey sites in the present study.

Knowledge of sites of contact where infected snails are prevalent is critical for preventing schistosomiasis transmission as human water contact with cercariae-infested water is a prerequisite of transmission. Like many other waterbodies in Sudan, residents and visitors can be observed to contact water. The main reasons for this are as follows. First, due to the intermit- 
tency of power-supply, electricity failure is common and the maintenance of water-supply systems is less than satisfactory. Thus, nearby residents, especially children (mainly boys), are left with no alternative other than to use available shallow water for bathing and recreational purposes that involve considerable exposure. Second, many young men supplement income by selling large quantities water collected from the White Nile. Third, some Sudanese inherited customs such as those associated with funerals or new-born ceremonies involve visiting the Nile shore in large family-groups and cleaning their faces, hands, and feet in the river. The 3 sites surveyed were suspected to be important for the transmission of $S$. mansoni and S. haematobium, based on observed human/water contact activities and the known presence of infected snails. Our longitudinal malacological surveys indicated that snail release of both human- and non-human trematode cercariae fluctuated seasonally.

It appears that March-June is the season of schistosomiasis transmission as reflected by the presence of human cercariae in the 2 intermediate-host snails. Our study shows that transmission pressures of the 2 types of Schistosomiasis were greater at the South Railway site and at the other 2 sites. Non-human trematodes were found to be naturally transmitted from Biomphalaria and Bulinus snails from January to June at the 3 sites,

The transmission pressure of Amphistome and Echinostome cercariae was more pronounced at the South Railway and North sites than at the South site. Broadly speaking, our findings indicated a low overall infection rate of snails with larval trematodes, which is in line with the findings of other studies and is attributed to low infection rates in natural snail populations due to high rates of parasite-induced mortality [26-28]. The low prevalence rates of infection could also be due to low parasite pressure due to infrequent miracidia and snail contact or to acquisition of a level of resistance to infection by hosts [29]. We found that the prevalence of infection and diversity of trematode fauna varied seasonally. In a previous study, temporal variations in larval trematodes infections in snails were ascribed to temperature and host behavioral differences $[30,31]$. Temperature influences the population biology of trematodes by inducing seasonal changes in the behavior and abundance of hosts, the longevity and infectivity of larval trematode stages, and in the development rates of larval and adult stages [30]. Nonetheless, information on trematode infections in freshwater snails is scarce and warrants further study.

In many malacological surveys, infected Biomphalaria and Bulinus snails were recovered throughout the year and infection rates fluctuated considerably [31-37]. In a similar investigation, Ibrahim studied the transmission pressure of schistosomiasis at the Blue Nile projects, Khartoum State and found that collected Biomphalaria pfeifferi and Bulinus truncatus liberated human cercariae over an extended period [38]. It was suggested this was due to an intensive population movement to the capital from different endemic areas. Given a background of extensive population movement to Khartoum by farmers and agricultural laborers and the complete absence of a national control program of schistosomiasis, the worms had been propagated to the city. Such factors appear to have exponentially and dramatically increased disease infection parameters in Khartoum State, as evidenced by recent surveys. In the present study, the 12-month survey showed that infected snails were present during March to June.

Understanding the dynamics of transmission in a given area must include knowledge of cercarial infection, production, and dynamics. Cercarial production and dynamics vary widely among human schistosomes and other trematodes. These variations result from the different demographic strategies parasites use and prevailing environmental conditions.

In conclusion, snail control is a critical consideration, particularly when transitioning from the schistosomiasis control to the elimination, together with the provision of safe water supplies and improved sanitary conditions. Thus, sound epidemiological surveys related to snail population and infection are essential in order to obtain tangible and realistic data regarding infection parameters. In particular, little study has been performed on the population dynamics of snails and many vector-related parameters remain unknown in Sudan. We conducted a longitudinal epidemiological survey on population dynamics of snail, infection rates, and related ecological factors.

To date, malacological studies have been undertaken mainly on irrigation canal systems rather than in main river basins. To the best of our knowledge, this is the first longitudinal malacological study to be conducted alongside the main basin of the White Nile. In our opinion, a properly designed control strategy implemented within the health system would lead to a considerable reduction in the transmission pressure of the 2 types of schistosomiasis in the study area. To achieve substantial control of schistosomiasis infection in the area, the follow- 
ing tactics are recommended. (1) Those living nearby and those that practice any type of water contact activities at the 3 sites surveyed sites should be examined microscopically. (2) Snail control is required at these sites to reduce vector density, i.e., if no snails are present no transmission can occur. (3) The 2 human cercariae types and the 2 monitored larval trematode parasites monitored in snails should be subjected to longitudinal investigation for at least a year. (4) The influence of population movements from schistosomiasis endemic areas and the epidemiologic and socioeconomic implications of these movements requires detailed study.

\section{CONFLICT OF INTERST}

The authors declare that they have no conflicts of interest.

\section{REFERENCES}

1. World Health Organization. Action Against Worms. Geneva, Switzerland. 2003

2. Omer AHS, Homilton PJS, Marshal TF and Draper CC. Infection with Schistosoma mansoni in the Gezira area of the Sudan. J Trop Med Hyg 1976; 79: 151-157.

3. Kardaman MW, Amin MA, Fenwick A, Cheesmonde AK, Dixon HG. A field trial using Praziquantel to treat Schistosoma mansoni and Schistosoma haematobium infection in Gezira, Sudan. Ann Trop Med Parasitol 1982; 77: 297-304. https://doi.org/10.1080/00034983.19 83.11811711

4. McCreesh N, Booth M. The Effect of increasing water temperatures on Schistosoma mansoni transmission and Biomphalaria pfeifferi population dynamics: an agent-based modelling study. PLoS One 2014; 9: e101462. https://doi.org/10.1371/journal.pone.0101462

5. Hilali AH. Transmission of Schistosoma mansoni in the Managil area, Sudan. Ph.D. Thesis, Department of Zoology, Faculty of Science, University of Khartoum. 1992.

6. Babiker A. Transmission and control of Schistosoma mansoni in the Gezira Irrigated area of the Sudan. Ph. D. thesis, Department of Zoology, Faculty of Science University of Khartoum. 1987.

7. Ahmed AA. Epidemiology of S. mansoni Infection in Gunaid Sugar Cane Scheme, Gezira State. Ph.D. thesis, Department of Zoology, Faculty of Science, University of Khartoum. 1998.

8. Ahmed AA. Schistosomiasis in Sugar cane schemes, Sudan. Journal of Basic Sciences. 2003; 3.

9. Ahmed AA. Schistosomiasis in Gunaid Sugar Cane Scheme, Sudan. Sudan Journal of Basic Sciences, 2007; 11: 139-147.

10. Ahmed AA. Schistosomiasis in Sudan, Historical Panorama and recent situation. Schistosomiasis Research Laboratory, Faculty of Science, University of Khartoum. 2008.

11. El Tash LA. Socioeconomic analysis of malaria burden in Gezira and Khartoum State. Ph.D. Thesis, Faculty of Economic and So- cial Studies, University of Khartoum. 2005.

12. Brown DS. Fresh Water Snails of Africa and Their Medical Importance. London, UK. Taylor and Fransis Ltd. 1980, pp 1-608.

13. Nidal AI, Henry M, Abdel Aziz ARM. Types of trematodes infecting freshwater snails found in irrigation canals in the East Nile locality, Khartoum, Sudan. Infect Dis Poverty 2016; 5: 16. https:// doi.org/10.1186/s40249-016-0108-y

14. Madsen H. Snail ecology. Theory and examples. Notes of Danish Schistosomiasis Laboratory, Charlottenlund, Denmark. 1982; 11.

15. Rabone M, Wiethase JH, Allan F, Gouvras AN, Pennance T, Hamidou AA, Webster BL, Labbo R, Emery AM, Garba AD, Rollinson D. Freshwater snails of biomedical importance in the Niger River Valley: evidence of temporal and spatial patterns in abundance, distribution and infection with Schistosoma spp. Parasite Vectors 2019; 12: 498. https://doi.org/10.1186/s13071-0193745-8

16. Ndione RA, Diop D, Riveau G, Ba CT, Jouanard N. Role of environmental parameters on the density of intermediate host snails of human schistosoma during the year in the commune of Richard-Toll, Senegal. Med Sante Trop. 2018; 28: 158-164. https://doi. org/10.1684/mst.2018.0795.

17. Karoum KOA. Trails on biological control of the intermediate host of schistosoma in Gezira Agriculture Scheme by competitor snail species. Ph.D. thesis, Faculty of Veterinary Sciences, University of Khartoum. 1988.

18. FMOH, Annual Health Statistic Report 2005-2006. Khartum, Sudan. Federal Ministry of Health. 2006.

19. World Health Organization. The Control of Schistosomiasis: Second Report of the WHO Expert Committee. Report of the WHO Expert Committee. Geneva, Swizeland. World Health Organization. 1993, pp 1-86.

20. Mohamed R. Distribution of fresh water snails and transmission pattern of Schistosoma mansoni in a low endemic area. M. Sc. Thesis, Department of zoology, Faculty of Science, University of Khartoum. 1999.

21. Frandsen F, Christensen NO. An introductory guide to identification of cercariae from African freshwater snails with special reference to cercariae of trematode species of medical and veterinary importance. Acta Trop 1984; 4: 181-202.

22. O'Keeffe JH. Population biology of the freshwater snail Bulinus globosus on the Kenya Coast. II. Feeding and density effects on population parameters. J Appl Ecology 1985; 34: 534-543. https://doi. org/10.2307/2403329

23. Appleton CC. The influence of temperature on the life-cycle and distribution of Biomphalaria pfeifferi (Krauss, 1848) in south-eastern Africa. Intern J Parasitol 1977; 7: 335-345. https://doi.org/10.1016/ 0020-7519(77)90057-1

24. Webbe G. Biology of intermediate hosts of schistosomiasis, with particular reference to control of transmission. Ann Trop Med Parasitol 1964; 58: 228-233. https://doi.org/ 10.1080/00034983.1964.11686237.

25. Manjing BK. Snail population fluctuations in relation to S. mansoni transmission in Gezira Irrigated Area. M. Sc thesis, University of Khartoum, Sudan. 1978. 
26. Fenwick A. The control of Schistosoma mansoni on a sugar estate in Tanzania. E Afr Med J 1971; 48: 447-449.

27. Babiker A, Fenwick A, Daffala AA and Amin A. Facility and seasonality of Schistosoma mansoni transmission in Gezira irrigated area Sudan. J Trop Med Hyg 1985; 88: 57-163.

28. Macher GA. Observation on micro epidemiology of urinary schistosomiasis in Nuba Mountains, Southern Kordfan State, Sudan. M.Sc. Thesis, Faculty of Science, Department of zoology, University of Khartoum. 2005.

29. Kigadye ESP. Studies on larval digeneans infecting freshwater snails. M.Sc thesis, University of Dar es Salam, Tanzania. 1998, pp 161.

30. Toledo R, Munoz- Antoli C, Perez M and Esteban JG. Larval trematode infections in freshwater gastropods from the Albufera natural park in Spain. J Helminthol 1998; 72: 79-82. https://doi.org/ 10.1017/s0022149x00001024.

31. Sousa WP. Interspecific interaction of larval trematode parasites of freshwater marine snails. American Zoologist 1992; 32: 583-592.

32. Begon ML, Harper L, Townsend CR. Ecology. 2nd ed. Oxford, UK. Blackwell Publishers. 1990.
33. Al-Kandari WY, Abdul-Salam J, Meakins R. Temporal variation in the infection of a population of Cerithidea cingulata by larval trematodes in Kuwait Bay. J Helminthol 2000; 74: 17-22.

34. Esch GW, Fernandez JC. Snail- trematode infections and parasite community dynamics in aquatic systems: a review. Am Midl Nat 1994; 131: 209-237. https://doi.org/10.2307/2426248

35. McCullough FS. The distribution of Schistosoma mansoni and $S$. haematobium in East Africa. Trop Geog Med 1972; 24: 199-207.

36. Erko B, Tedla S, Petros B. Transmission of intestinal schistosomiasis in Bahir Dar, northwest Ethiopia. Ethiop Med J 1991; 29: 199211.

37. Okafor FC. Schistosoma haematobium cercariae transmission patterns in freshwater systems of Anambra State, Nigeria. Angew Parasitol 1990; 31: 159-166.

38. Ibrahim NA. Malacological observation related to Schistosomiasis transmission with special emphasis on parasite aggregation and dynamics in some water bodies in Khartoum state. M. Sc. Thesis, Department of Zoology, Faculty of Science, University of Khartoum. 2008. 
